\title{
RATIOS DE LIQUIDEZ Y CUENTAS POR COBRAR: ANÁLISIS COMPARATIVO DE LAS EMPRESAS DEL SECTOR LÁCTEO QUE COTIZAN EN LA BOLSA DE VALORES DE \\ LIMA
}

\author{
LIQUIDITY AND ACCOUNTS RECEIVABLE RATIOS: COMPARATIVE ANALYSIS OF \\ COMPANIES IN THE DAIRY SECTOR TRADING IN THE BOLSA DE VALORES DE LIMA \\ Carlos Alberto Vásquez Villanueva \\ Universidad César Vallejo \\ Lima, Perú \\ carlosvasquezv19@gmail.com \\ Marylin Jhosmit Huaman Tito \\ Universidad César Vallejo \\ Lima, Perú \\ mhuamanti@ucvvirtual.edu.pe \\ Otto Franklin Terry Ponte \\ Universidad César Vallejo \\ Lima Perú \\ ottoterry@gmail.com \\ Carlo Stefano Cerna Carrazco \\ Universidad César Vallejo \\ Lima, Perú \\ ccernaca99@ucvvirtual.edu.pe
}

Fecha de recepción: 11/01/2021 - Fecha de aprobación: 16/03/2021

DOI: https://doi.org/10.36995/j.visiondefuturo.2021.25.02R.006.es

\section{RESUMEN}

El estudio tuvo como finalidad analizar las cuentas por cobrar y la liquidez, en las empresas del sector lácteo que cotizan en la BVL; la metodología empleada fue de tipo descriptiva comparativa, de diseño no experimental con corte transversal. La técnica que se utilizó fue el análisis documental y como instrumento se empleó la ficha de análisis; por otro lado, la muestra no probabilística estuvo constituida por 20 estados financieros anuales, compuestos a su vez por dos empresas del sector lácteo de los años 2015 al 2019; sobre esta base se calcularon los indicadores financieros de comparación. Los resultados determinaron que la empresa Leche Gloria SA, logró obtener una mejor suficiencia de cobro por la velocidad en la recuperación de sus créditos otorgados, mientras que Laive SA tardó en recuperar el efectivo de las ventas realizadas; en cuanto a la liquidez las dos empresas contaron con buena capacidad de pago para hacer frente a sus obligaciones y deudas a corto plazo, superando el rango estimado. Se concluyó, que al contar con buenos estándares de cobranza, las empresas obtuvieron una liquidez considerable para realizar los pagos correspondientes y evitar el estancamiento de la producción según la actividad económica.

PALABRAS CLAVE: Cuentas por cobrar; Liquidez; Ratios Financieros.

\section{ABSTRACT}

The purpose of the study was to analyze accounts receivable and liquidity in dairy sector companies listed on the BVL; The methodology used was descriptive - comparative, of a non-experimental design with a cross section. The technique that was used was the

\footnotetext{
"Visión de Futuro" Año 18, Volumen No 25 N², Julio - Diciembre 2021 - Pág 195 - 214

URL de la Revista: http://visiondefuturo.fce.unam.edu.ar/index.php/visiondefuturo/index

URL del Documento: https://visiondefuturo.fce.unam.edu.ar/index.php/visiondefuturo/issue/view/21

ISSN 1668 - 8708 - Versión en Línea

E-mail: revistacientifica@fce.unam.edu.ar 
documentary analysis and the analysis sheet was used as an instrument; On the other hand, the non-probabilistic sample consisted of 20 annual financial statements, in turn made up of two companies in the dairy sector from 2015 to 2019; On this basis, the financial comparison indicators were calculated. The results determined that the company Leche Gloria SA, managed to obtain a better collection sufficiency due to the speed in the recovery of its loans granted, while Laive SA was slow to recover the cash from the sales made; Regarding liquidity, the two companies had good payment capacity to meet their obligations and shortterm debts, exceeding the estimated range. It was concluded that by having good collection standards, companies obtain considerable liquidity to make the corresponding payments and avoid production stagnation according to economic activity.

KEY WORDS: Accounts Receivable; Liquidity; Financial ratios.

\section{INTRODUCCIÓN}

Las empresas lácteas a nivel internacional han tenido un crecimiento económico importante, por tal motivo es considerado uno de los grupos industriales con mayor flujo económico anual del sector alimenticio; con respecto a lo anterior, Saíz Bear (2017) señala que la demanda es el factor principal de incremento productivo y la razón por el que las ventas a crédito han venido incrementándose en el tiempo, el escenario internacional expone que 101 empresas lácteas de Europa, vienen tomando medidas comerciales que ayuden a mantener un promedio de rango mínimo del $80 \%$ en la liquidez inmediata, con el objetivo de cumplir con sus obligaciones financieras; lo cual quiere decir que el crecimiento de las ventas en las empresas genera mayor liquidez, adoptando un seguimiento continuo para el cumplimiento de las deudas a corto plazo según la capacidad de pago.

Además, existen diferencias en el tratamiento de la liquidez en los tipos de empresas internacionales, esto es importante para determinar parámetros a los resultados obtenidos, Amat Salas (2017) describe a 75 de las mejores empresas lácteas de Europa en el 2017, de las cuales señala que las productoras medianas y grandes tienen un promedio de liquidez del $1.52 \%$ en comparación con el $1.60 \%$ de las pequeñas empresas; con referencia a esto, resalta que las cuentas por cobrar tienen un promedio de 45 días en el proceso de cobros, esta información es relevante si se busca mejorar el manejo de la liquidez ante las obligaciones empresariales.

En el contexto nacional, el sector lácteo es una de las actividades más importantes en la economía junto a la industria avícola y ganadera, por lo que representa una fuente importante de generación de empleo debido a la creciente demanda. Pineda Portugal (2014) menciona que las empresas Nestlé SA, Leche Gloria SA y Laive SA proveen el $90 \%$ del

\footnotetext{
“Visión de Futuro" Año 18, Volumen No 25 N², Julio - Diciembre 2021 - Pág 195 - 214

URL de la Revista: http://visiondefuturo.fce.unam.edu.ar/index.php/visiondefuturo/index

URL del Documento: https://visiondefuturo.fce.unam.edu.ar/index.php/visiondefuturo/issue/view/21

ISSN 1668 - 8708 - Versión en Línea

E-mail: revistacientifica@fce.unam.edu.ar
} 
mercado, el 10\% restante está compuesto por productoras artesanales; eso quiere decir, que es importante determinar el nivel de ventas que se realizan anualmente para generar mayores ingresos.

Esto se encuentra en concordancia con lo recomendado por Solano Durán (2018), quien expresa que utilizar herramientas financieras puede mejorar el carácter económico sobre las cuentas por cobrar buscando disminuirlos a un 15\%, lo cual necesita una función de seguimiento a los clientes para el respectivo cobro por diversos medios, ya que esto implica a un activo que se puede transformar rápidamente a un efectivo monetario; debido a esto, las empresas industriales del sector lácteo son muy importantes tanto en la economía como en la salud de cada país mejorando la tasa de crecimiento económico.

A nivel local, las empresas lácteas que se utilizaron para realizar el informe de investigación, según la última información de la Bolsa de Valores de Lima (2020), fueron la empresa Laive SA, ubicada en el distrito de Ate, la cual se dedica a la elaboración de la leche y sus derivados como el yogurt, queso, mantequillas, entre otras mercancías para la venta y distribución a nivel nacional. La empresa en el periodo 2019 tuvo como resultado un índice de liquidez del 1.09 respecto al activo corriente sobre el pasivo corriente; en cuanto a las cuentas por cobrar (S/ 67'610,000), sobre esto Bendezú Rivera (2019) refiere que las cuentas por cobrar de la empresa hace 6 años eran mayor a las cuentas por pagar en un $55.80 \%$, lo que generó un índice de liquidez bajo del $48 \%$ promedio establecido, con consecuencias de llevar a cambiar drásticamente la manera de gestionar sus cuentas exigibles.

Por su parte la empresa Leche Gloria SA, ubicada en el distrito de La Victoria, se dedica a la preparación, envasado, manufactura, compra y venta, importación y exportación de productos derivados de la leche, productos compuestos por frutas y verduras, entre otros. En el periodo 2019 obtuvo un índice de liquidez de 1.60\% y las cuentas por cobrar con un equivalente (S/ 300’090,000). Córdova Pacheco (2018) menciona que en los últimos periodos la empresa muestra un nivel de liquidez promedio del $77 \%$, lo cual tiene una cobertura de manera estándar sobre sus obligaciones financieras a corto plazo; en cuanto a las cuentas por cobrar menciona que las políticas de créditos son de mayor agresividad año tras año, siendo ligeramente menores a las cuentas por pagar hasta el año 2017.

Todo lo anterior resalta la importancia de realizar un análisis de las cuentas por cobrar en dichos periodos, esto ayudará a determinar los aciertos y falencias de las actividades que se emplearon para mejorar la liquidez de las empresas industriales del sector lácteo. Por tal motivo y a través de un análisis descriptivo se formuló el siguiente problema: ¿Cuál es la

\footnotetext{
"Visión de Futuro" Año 18, Volumen No 25 N², Julio - Diciembre 2021 - Pág 195 - 214

URL de la Revista: http://visiondefuturo.fce.unam.edu.ar/index.php/visiondefuturo/index

URL del Documento: https://visiondefuturo.fce.unam.edu.ar/index.php/visiondefuturo/issue/view/21

ISSN 1668 - 8708 - Versión en Línea

E-mail: revistacientifica@fce.unam.edu.ar
} 
situación financiera de las cuentas por cobrar y la liquidez, en las empresas del sector lácteo que cotizan en la BVL? Y de este se ramifican los específicos: ¿Cuál es el estado de las cuentas por cobrar, en las empresas del sector lácteo que cotizan en la BVL?, y ¿Cuál es el estado de la liquidez, en las empresas del sector lácteo que cotizan en la BVL?

La finalidad del informe fue realizar el análisis de las cuentas por cobrar y la liquidez de las empresas del sector lácteo que cotizan en la BVL y de ese modo comparar los resultados y factores determinantes; así mismo, se llegó a identificar qué empresa utiliza mejor sus estrategias o recursos con la finalidad de obtener mejores resultados ante la competencia, así como la determinación de variantes en las actividades económicas, cuando se genera liquidez ante las obligaciones financieras en cada periodo. Es importante también porque otorga la oportunidad de explorar una realidad con diversos puntos de vistas, aplicando en un informe original, innovador y que brinde conocimiento sobre una situación problemática.

Los beneficiados por la realización de este estudio son los accionistas al momento de invertir capital en las entidades cotizantes, así como las mismas empresas que podrán obtener conocimiento detallado sobre los factores que afectan a los resultados; al igual que otros investigadores que puedan realizar este tipo de informe. Por otro lado, se manifiesta que la investigación es viable debido a que la información obtenida se encuentra en libre acceso y se tienen los recursos necesarios para su realización.

Por lo antes expuesto, el propósito del estudio es analizar el ámbito de las cuentas por cobrar y la liquidez mediante ratios financieros, en las empresas del sector lácteo que cotizan en la BVL.

\section{DESARROLLO}

\section{Principales bases teóricas}

Las cuentas por cobrar son sumamente importantes para las organizaciones debido a que es una fuente de ingresos monetarios y clave para mantener un flujo de caja saludable. Guajardo Cantú y Andrade de Guajardo (2014) indican que es un recurso económico, propiedades y derechos de cada empresa, del cual se podrá generar algún beneficio a corto plazo. Es decir, que este activo puede generar beneficios al llevar un control para la buena gestión de las cobranzas, por lo cual ayudará a la empresa a mejorar el crecimiento de sus ventas y liquidez.

Además, es la obligación crediticia por la compra de bienes o servicios suscrita por un cliente, a la vez puede ser a corto o largo plazo; Stam y Westerman (2018) sostienen que se trata de una inversión con los clientes mediante un crédito comercial y la forma de gestionar este crédito influye en la cobranza para evitar los atrasos; por su parte Munene (2018)

\footnotetext{
“Visión de Futuro" Año 18, Volumen No 25 N², Julio - Diciembre 2021 - Pág 195 - 214

URL de la Revista: http://visiondefuturo.fce.unam.edu.ar/index.php/visiondefuturo/index

URL del Documento: https://visiondefuturo.fce.unam.edu.ar/index.php/visiondefuturo/issue/view/21

ISSN 1668 - 8708 - Versión en Línea

E-mail: revistacientifica@fce.unam.edu.ar
} 
infiere que poseen un aspecto importante en las finanzas, debido a que afecta proporcionalmente a la liquidez y rentabilidad; así mismo, tiene principios en las cuales se debe regir las empresas para evaluar la capacidad de pago de los clientes con cuentas envejecidas por cobrar, usando criterios para analizar la condición económica al establecer créditos comerciales, evaluaciones del riesgo por incumplimiento para no afectar la solidez financiera. Por lo tanto, ambos autores muestran lo vital que son las cuentas por cobrar para el funcionamiento de la empresa ante las obligaciones financieras mediante el cobro a sus respectivos clientes.

Como dimensiones de las cuentas por cobrar se consideraron:

La rotación de cuentas por cobrar es importante tener un control sobre las cobranzas que se deben realizar para incrementar el efectivo en la empresa. Pandoyo (2019) define a la rotación de cuentas por cobrar como una medida de la cantidad de veces, en el que una empresa realiza sus cobranzas durante el periodo contable; esto se logra calcular dividiendo las ventas con las cuentas por cobrar en cada año de investigación. Esto da a entender, que este ratio ayuda a promediar las veces que una empresa puede convertir sus activos exigibles a dinero para incrementar la liquidez en el periodo.

El periodo promedio de cobranza permite conocer el número de días que la empresa se demora en cobrar el activo exigible. Wafula et ál. (2019) definen que es el plazo en días en que una empresa se tarda en cobrar a sus clientes; dicho de otra forma, este indicador muestra el número de días promedio que tardan en pagar los clientes que se está financiando, por lo cual, es importante que la entidad tenga en cuenta el tiempo que se demora la cobranza para la obtención del efectivo.

Es fundamental determinar un plazo prudente de la cobranza para evitar una acumulación de cuentas incobrables al futuro; al respecto, Ortiz Taipe (2019) mencionan que el periodo promedio cobranza es el plazo en el tiempo en donde el cliente se tarda en efectuar el pago de la venta, este debe ser pertinente ya que será medido mediante las cuentas por cobrar entre las ventas al crédito por los días del año. Este indicador ayuda a medir el promedio de los días que una empresa emplea para poder realizar sus cobranzas a los clientes deudores por la venta de un bien o servicio a crédito.

La variable liquidez es muy importante en las empresas, ya que resulta una herramienta para controlar la capacidad para hacerse responsable de sus deudas con terceros. Peralta Gamboa (2018) señala que la liquidez es el volumen que tienen las empresas para poder afrontar sus deudas y obligaciones financieras en periodos determinados con las cantidades establecidas con los proveedores, clientes y entidades financieras con quienes se realizan

\footnotetext{
“Visión de Futuro" Año 18, Volumen No 25 N², Julio - Diciembre 2021 - Pág 195 - 214

URL de la Revista: http://visiondefuturo.fce.unam.edu.ar/index.php/visiondefuturo/index

URL del Documento: https://visiondefuturo.fce.unam.edu.ar/index.php/visiondefuturo/issue/view/21

ISSN 1668 - 8708 - Versión en Línea

E-mail: revistacientifica@fce.unam.edu.ar
} 
operaciones económicas a corto plazo. Es decir, ayuda a mantener un parámetro que se debe cumplir para poder cumplir con las actividades a lo largo del periodo laboral.

Se resalta la importancia de que una liquidez óptima es fundamental para todas las empresas, debido a su condición de medidor de solvencia para saldar las obligaciones financieras en cada periodo de actividad. Opuku Ware (2015) indica que las decisiones a aplicar en una gestión que influyen en la eficacia de la liquidez, da prioridad a la gestión de activos corrientes, pasivos corrientes y la correlación existente; también implica planificar y controlar los activos corrientes a tal grado que elimine la incapacidad de cumplir obligaciones debidas a corto plazo, para lo cual se debe tener un control constante en los diferentes tipos de indicadores ramificados de esta variable.

Herramientas que pueden ayudar son los ratios de liquidez, ya que miden puntos diferentes dentro de la liquidez según los activos que se poseen. Durrah et ál. (2016) definen a la liquidez como la velocidad de transferencia de los activos a efectivo, donde determinados indicadores miden la capacidad de las empresas para cumplir con sus obligaciones financieras a corto plazo; los resultados dan mayor entendimiento del estado en que se encuentran las empresas en el mercado financiero.

Como dimensiones de la liquidez se tienen:

La liquidez corriente ayuda a medir la capacidad de una empresa con sus activos y pasivos pertenecientes a un periodo contable. Castañeda Vásquez (2018) manifiestan que la liquidez corriente es un indicador que refleja la técnica de la entidad para poder pagar las deudas en un determinado momento, ya que a mayor resultado mejor es la capacidad de la compañía para encargase de sus deudas. El ratio se basa en el resultado 1, si es mayor tiene buena capacidad de pago, si es igual puede cubrir sus deudas y en caso sea menor tiene mala capacidad por falta de liquidez. Así mismo, ayuda a mantener un nivel óptimo para el cumplimiento de sus deudas corrientes financieras.

Por consiguiente, este ratio brinda un panorama más extenso en el manejo de los recursos dentro de un periodo contable. Moreno Fernández (2014) indica que la liquidez corriente se determina dividiendo el valor del activo corriente entre el valor del pasivo corriente y como resultado son las veces que el activo tiene sobre el pasivo; así que, controlar este indicador da más oportunidades de manejar el efectivo para el cumplimiento de los costos para el funcionamiento de la empresa.

La prueba ácida indica la capacidad que tiene la empresa con sus activos líquidos excluyendo al inventario, para cubrir sus deudas a corto plazo. Marsha y Murtaqi (2017) expresan como una interpretación más conservadora del índice de liquidez corriente, aunque este ratio brinda una evaluación más rigurosa a la capacidad de una empresa para

\footnotetext{
"Visión de Futuro" Año 18, Volumen No 25 N², Julio - Diciembre 2021 - Pág 195 - 214

URL de la Revista: http://visiondefuturo.fce.unam.edu.ar/index.php/visiondefuturo/index

URL del Documento: https://visiondefuturo.fce.unam.edu.ar/index.php/visiondefuturo/issue/view/21

ISSN 1668 - 8708 - Versión en Línea

E-mail: revistacientifica@fce.unam.edu.ar
} 
pagar los pasivos corrientes, incluyendo la eliminación del inventario en la fórmula, considerado el menos líquido y convertible a efectivo del activo corriente, del cual es más probable obtener pérdidas; por lo que, ayuda a medir el activo liquido de mejor conversión para hacer frente a las obligaciones financieras.

Por otro lado, Herrera Freire et ál. (2016) indican que este ratio es similar al de solvencia, pero a la vez es el activo de menor liquidez ya que dentro del activo corriente no se toma en cuenta el inventario. Es decir, esta razón es el menos líquido porque no se considera los inventarios.

La prueba defensiva ayuda a generar un resultado sólo con el efectivo monetario y de cuentas corrientes para poder hacerse cargo de las deudas a corto plazo. Wiwik Afridah (2018) define a la prueba defensiva como un medidor de la capacidad con la cual cuenta una empresa al momento de pagar obligaciones a corto plazo con el disponible más líquido y las cuentas corrientes en entidades financieras. El indicador permite dar un margen más detallado con el activo más líquido monetariamente para cubrir los pasivos con terceros a corto plazo.

\section{Metodología, presentación y análisis de datos}

La muestra para este estudio estuvo conformada por 10 estados de situación financiera y 10 estados de resultados de dos empresas del sector lácteo, como Laive SA y Leche Gloria SA que cotizan en la Bolsa de Valores de Lima desde el 2015 al 2019. Taherdoost (2017) define a la muestra como una característica relevante de una investigación, con el objetivo de hacer inferencias a una población por medio de la muestra para evitar errores bajo un tamaño adecuado. Por lo tanto, la muestra es una parte representativa de la población que es elegida mediante factores en la investigación.

Se empleó el muestreo no probabilístico por conveniencia, ya que las empresas seleccionadas fueron de fácil acceso por la información financiera que exponen de manera pública. Otzen y Manterola (2017) definen a las técnicas de muestreo de categoría no probabilístico como una elección de sujetos para el análisis, el cuál será sometido a ciertas características o criterios que sean necesarios y de donde los investigadores pueden obtener resultados válidos o confiables por no ajustarse a una certeza fortuita, por lo cual es importante realizar un análisis sin alterar los resultados obtenidos naturalmente en una investigación.

Las empresas peruanas que se tomaron en cuenta para el estudio son:

LAIVE S.A., ubicada en el distrito de Ate y LECHE GLORIA S.A., en el distrito de La Victoria, ambas residentes y cotizadoras.en la Bolsa de Valores de Lima.

\footnotetext{
"Visión de Futuro" Año 18, Volumen No 25 N², Julio - Diciembre 2021 - Pág 195 - 214

URL de la Revista: http://visiondefuturo.fce.unam.edu.ar/index.php/visiondefuturo/index

URL del Documento: https://visiondefuturo.fce.unam.edu.ar/index.php/visiondefuturo/issue/view/21

ISSN 1668 - 8708 - Versión en Línea

E-mail: revistacientifica@fce.unam.edu.ar
} 
El estudio realizado fue de tipo descriptivo comparativo, porque se relata procedimientos y factores que se tomaron en cuenta para estas variables entre varios sujetos. Díaz Narváez y Calzadilla Núñez (2015) mencionan que este tipo de investigación opera al momento de medir las características, componentes o dimensiones en función de obtener la mayor precisión del estudio. En contraposición al autor, la descripción se eligió por la capacidad de reflejar a detalle la realidad de la situación financiera en ambas empresas limeñas del sector lácteo, por lo que la investigación pretende centrase en la recopilación de datos que describen la situación de las variables para identificar qué acciones toman cada entidad al manejar sus finanzas.

La técnica que se empleó en el informe fue el análisis documental, porque se analizó el Estado de Situación Financiera y el Estado de Resultado de los años 2015 al 2019 de las empresas del sector lácteo que cotizan en la Bolsa de Valores de Lima. Gómez Rodríguez et ál. (2016) indican que la técnica documental son mecanismos e instrumentos que se utilizan para reunir y medir información de forma organizada y que además permite la recopilación de información para enunciar las teorías que sustentan el estudio de los fenómenos y procesos; se entiende que la técnica es un conjunto de herramientas y medios utilizados para implementar el método, que sólo es aplicable a la ciencia.

A continuación, se analizó la variable cuentas por cobrar en el ámbito financiero mediante ratios según sus dimensiones que son la rotación de cuentas por cobrar, consultando los datos de la BVL, se comprobó una variación entre las empresas del sector lácteo de acuerdo a la figura presentada a continuación:

\footnotetext{
"Visión de Futuro" Año 18, Volumen No 25 N², Julio - Diciembre 2021 - Pág 195 - 214

URL de la Revista: http://visiondefuturo.fce.unam.edu.ar/index.php/visiondefuturo/index

URL del Documento: https://visiondefuturo.fce.unam.edu.ar/index.php/visiondefuturo/issue/view/21

ISSN 1668 - 8708 - Versión en Línea

E-mail: revistacientifica@fce.unam.edu.ar
} 


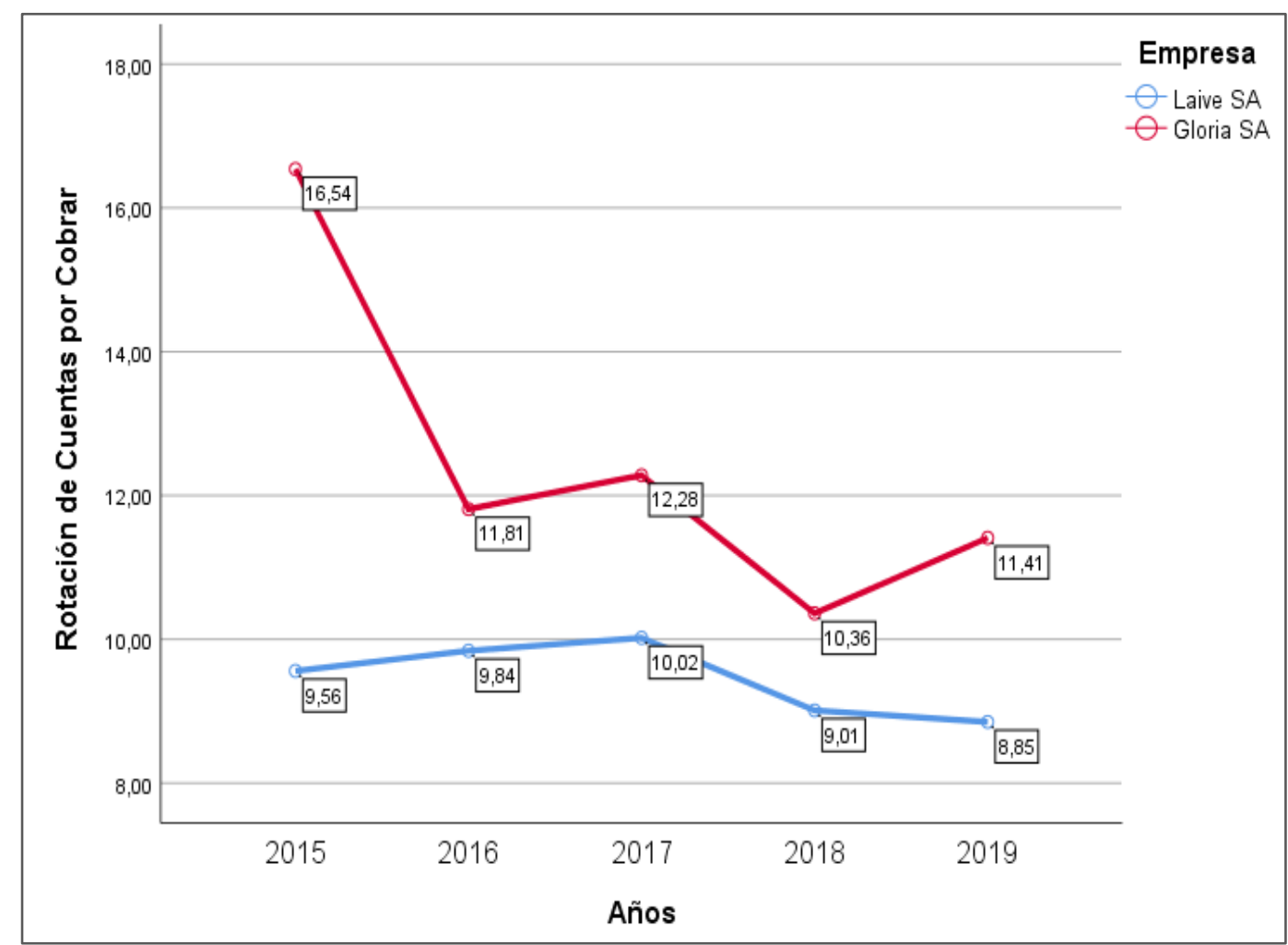

Figura $\mathrm{N}^{\circ} 1$. Análisis comparativo de la rotación de las cuentas por cobrar

Fuente: Elaboración Propia a partir de datos de la BVL (2015 - 2019)

De acuerdo a la figura 1, se observa que en el periodo 2015 al 2019, los valores más bajos de rotación de cuentas por cobrar, en las empresas productivas de lácteos, corresponden a la empresa Laive SA con índices de 9,56 en el 2015, 9,84 en el 2016, 10,02 en el 2017, 9,01 en el 2018 y 8,85 en el 2019. Los valores más altos en todo el periodo 2015 al 2019 fueron registrados por la empresa Leche Gloria SA con índices de 16,54 en el 2015, 11,81 en el 2016, 12,28 en el 2017, 10,36 en el 2018 y 11,41 en el 2019. Por otro lado, el valor del promedio para la rotación de las cuentas por cobrar fue mayor para la empresa Gloria SA con 12.48; por su parte, Laive SA presentó un promedio del índice de rotación de cuentas por cobrar de 9,46 .

En relación al dictamen del año 2015, obtenido de la página web de la Bolsa de Valores de Lima, se pudo observar que la empresa Leche Gloria SA demostró tener una mayor capacidad y mejor control para realizar los cobros de 17 veces anualmente. Esto fue debido a que cuentan con políticas de cobranza bien establecidas, donde el tratamiento del crédito con los clientes era de 8 a 60 días, contando con un $80 \%$ facturas aún no vencidas al final del periodo.

Además la gerencia contó con garantías emitidas por los clientes (S/ 29’279,000) debido al riesgo crediticio por parte de los clientes con dificultades para pagar (S/ 18'437,000)

\footnotetext{
"Visión de Futuro" Año 18, Volumen No 25 N 2, Julio - Diciembre 2021 - Pág 195 - 214

URL de la Revista: http://visiondefuturo.fce.unam.edu.ar/index.php/visiondefuturo/index

URL del Documento: https://visiondefuturo.fce.unam.edu.ar/index.php/visiondefuturo/issue/view/21

ISSN 1668 - 8708 - Versión en Línea

E-mail: revistacientifica@fce.unam.edu.ar
} 
afectando a la recaudación de las cuenta por cobrar. El punto más bajo de Leche Gloria SA se encontró en el 2018, y según al dictamen presentado es donde se entregó mayor crédito representado al $11 \%$ del total de ventas realizadas, teniendo una rotación de 10 veces al ser el año de menores ventas.

Por otra parte, en el dictamen del año 2017 de Laive SA siendo el menor a comparación a la otra empresa, tiene un nivel de rotación de cobranzas de 11 veces, debido a que algunas cuentas por cobrar están garantizadas por medio de cartas fianzas, depósitos en garantía e hipotecas (S/39'354,000) después de haber determinado el deterioro de casi un $20 \%$ que superan el plazo mayor a los 180 días de vencimiento.

Por consiguiente, el periodo promedio de cobranzas tuvo una variación considerable en los años evaluados del sector lácteo, como se muestra en la siguiente figura:

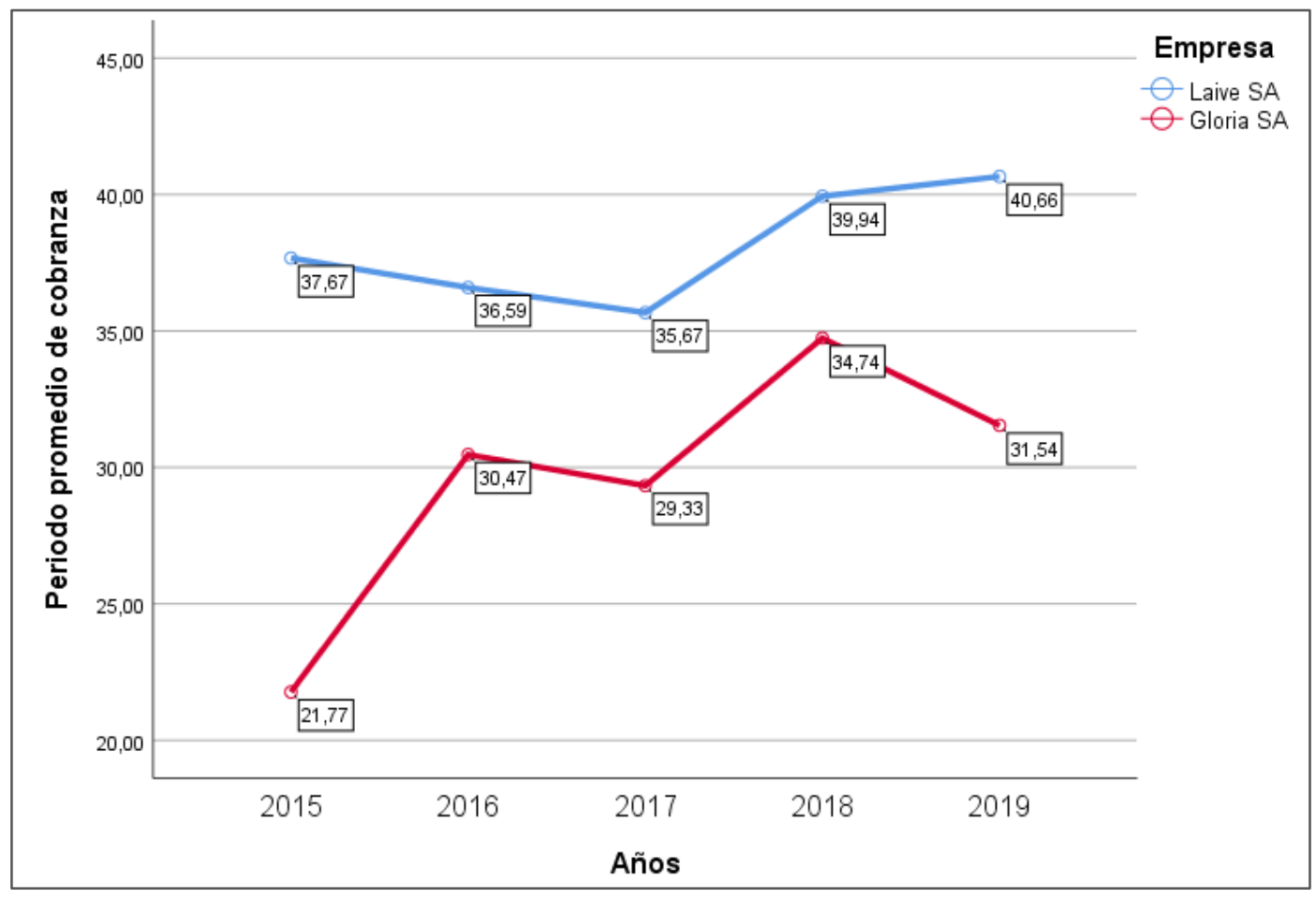

Figura $N^{\circ}$ 2. Análisis comparativo del periodo promedio de cobranza

Fuente: Elaboración Propia a partir de datos de la BVL (2015 - 2019)

De acuerdo a la figura 2, dentro del periodo 2015 al 2019, los valores más bajos del periodo promedio de cobranza, en las empresas productivas de lácteos, corresponden a la empresa Leche Gloria SA con 21,77 en el 2015, 30,47 en el 2016, 29,33 en el 2017, 34,74 en el 2018 y 31,54 en el 2019; en cambio los valores más altos en todo el periodo 2015 al 2019 fueron registrados por la empresa Laive SA con 37,67 en el 2015, 36,59 en el 2016, 35,67 en el 2017, 39,94 en el 2018 y 40,66 en el 2019. Por otro lado, el valor promedio para el periodo 
promedio de cobranza fue mayor para la empresa Laive SA con 38,11 ; por su parte, Leche Gloria SA presentó un promedio de 29,57.

En relación al dictamen del año 2019 la empresa Laive SA tuvo un periodo promedio de cobranza de 41 días, debido a que las ventas realizadas a los distribuidores y autoservicios tienen un crédito de 14 a 60 días, a quienes la empresa les realiza una evaluación de créditos 2 veces al año. Además la compañía tuvo cuentas por cobrar que estaban garantizadas por cartas fianzas y depósitos en garantía (S/ 47’977,000).

En caso de Leche Gloria SA, se reflejó en el año 2018 que contaba con 35 días en su promedio periodo de cobranza en los últimos 5 años, debido a que contaron con una mejor gestión de los créditos otorgados y las cobranzas en menor tiempo, contando con el $71 \%$ de las ventas aún no vencidas. En la empresa estimó una cobranza dudosa (S/ 18'637,000) lo que en consecuencia la gerencia utilizó las garantías depositadas por los clientes para controlar el deterioro de los cobros.

Respecto a la variable liquidez, se cuenta con la primera dimensión donde se muestra que las empresas son favorables pasando el rango estimado, de acuerdo a la siguiente figura:

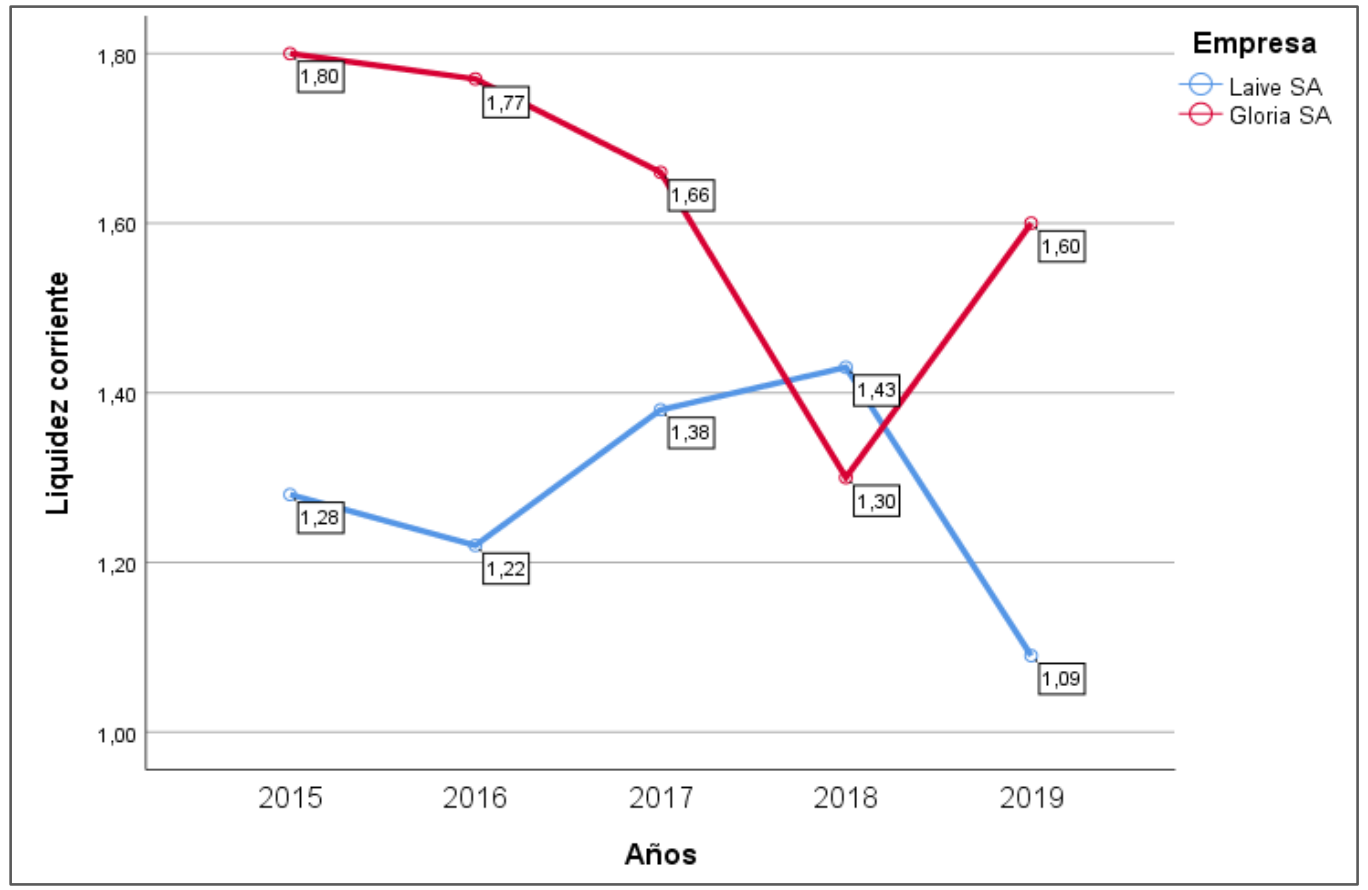

Figura $\mathrm{N}^{\circ} 3$. Análisis comparativo de la liquidez corriente

Fuente: Elaboración Propia a partir de datos de la BVL (2015 - 2019)

La figura 3, muestra los índices de liquidez corriente en las empresas del sector productivo lácteo en el periodo 2015 al 2019; los valores más altos fueron registrados por la empresa Leche Gloria SA, partiendo con un 1,80 en el año 2015, el cual representa el índice de liquidez corriente más alto dentro del periodo, 1,77 en el año 2016, 1,66 en el 2017 y 1,60 en "Visión de Futuro" Año 18, Volumen No 25 N², Julio - Diciembre 2021 - Pág 195 - 214 URL de la Revista: http://visiondefuturo.fce.unam.edu.ar/index.php/visiondefuturo/index URL del Documento: https://visiondefuturo.fce.unam.edu.ar/index.php/visiondefuturo/issue/view/21 
el 2019; en cambio los valores de liquidez corriente más bajos se registraron por parte de la empresa Laive SA, con 1,28 en el 2015, 1,22 en el 2016, 1,38 en el 2017 y 1,09 en el 2019; cabe señalar de que en el año 2018 el resultado se invirtió para las dos empresas, Laive SA supera a Leche Gloria SA con un índice de liquidez corriente de 1,43 y Leche Gloria desciende a índice de 1,30. Por otro lado, el promedio fue mayor para Leche Gloria SA con un índice de 1,62, comparado al índice de liquidez corriente de 1,28 obtenido por Laive SA. El punto más alto fue de Leche Gloria SA en el año 2015, según el dictamen de dicho año, con un resultado de 1,80 puntos porcentuales, esto quiere decir que la capacidad para cubrir sus obligaciones financieras a corto plazo es basto, ya que tendría $80 \%$ más en los activos corrientes después de saldar con el pasivo corriente. Esto es debido a que los inventarios equivalen un $53 \%$ del activo a corto plazo, en especial el costo de la materia primas, auxiliares y otros insumos que es equivalente al $33 \%$ y la materia prima y auxiliar por recibir en el próximo trimestre. En el año 2018, el resultado menor fue de 1,3 debido que a pesar de haber mantenido un inventario alto; en los pasivos corrientes encontramos un aumento de las cuentas por pagar comerciales en un $40 \%$.

En cuanto a Laive SA el punto más alto fue en el 2018, con un resultado de 1,43 debido a que en el pasivo corriente hubo un incremento en las cuentas por pagar, por la compra de materia prima y suministros para la fabricación, incluso productos terminados en el almacén listos para la venta. El punto más bajo se mostró detallado en el año 2019 con 1,09 de liquidez corriente, debido que, a pesar de tener un elevado porcentaje en el inventario y cuentas por pagar, las cuentas por cobrar es el que determina la disminución en este periodo.

\footnotetext{
"Visión de Futuro" Año 18, Volumen No 25 N², Julio - Diciembre 2021 - Pág 195 - 214

URL de la Revista: http://visiondefuturo.fce.unam.edu.ar/index.php/visiondefuturo/index

URL del Documento: https://visiondefuturo.fce.unam.edu.ar/index.php/visiondefuturo/issue/view/21

ISSN 1668 - 8708 - Versión en Línea

E-mail: revistacientifica@fce.unam.edu.ar
} 


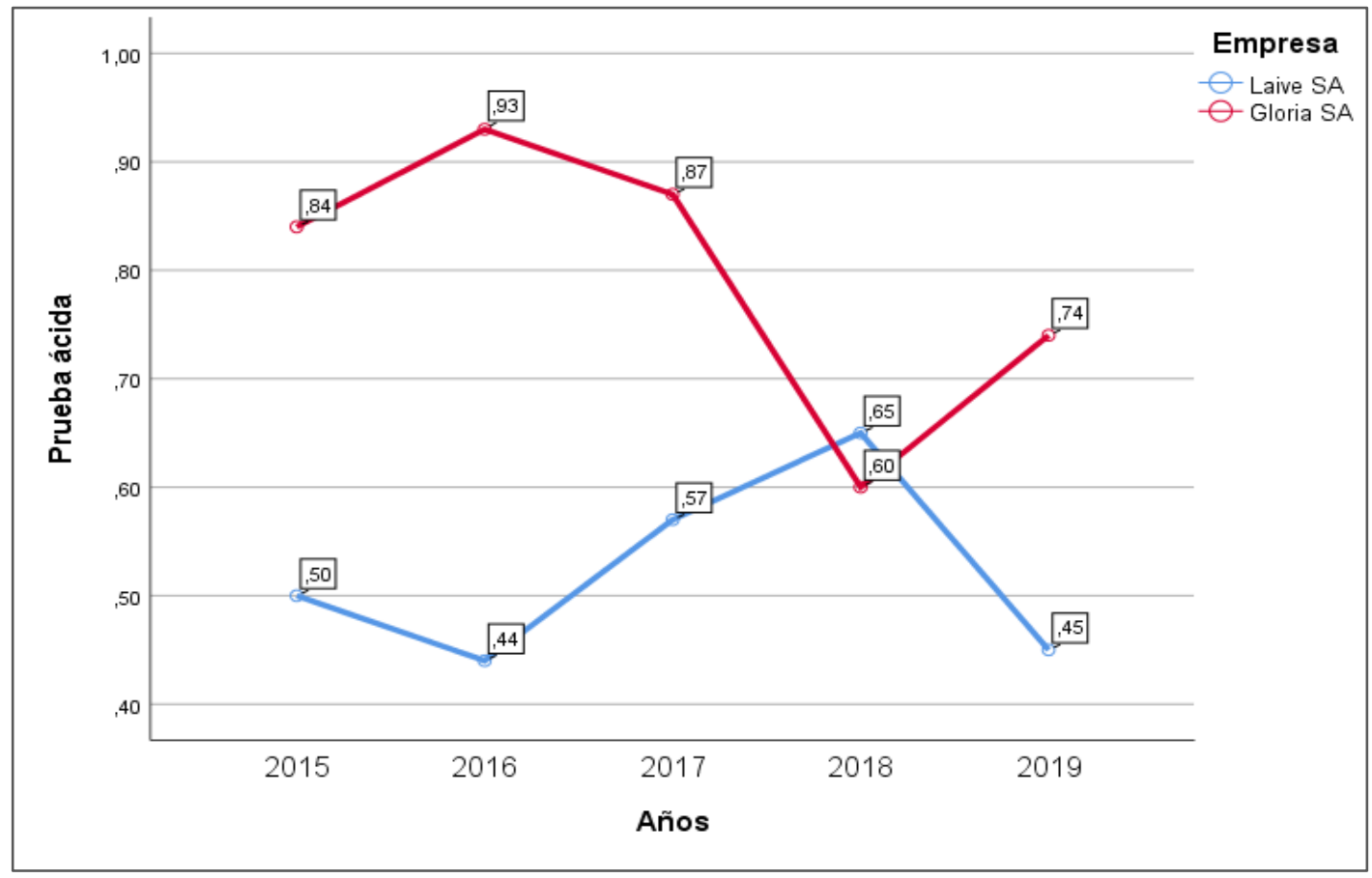

Figura $N^{\circ} 4$. Análisis comparativo de la prueba ácida

Fuente: Elaboración Propia a partir de datos de la BVL (2015 - 2019)

La figura 4, muestra los índices de prueba ácida de las empresas del sector productivo lácteo en el periodo 2015 al 2019; los valores más altos fueron registrados por la empresa Leche Gloria SA, partiendo con un 0,84 en el año 2015, 0,93 en el año 2016, el cual representa el índice de prueba ácida más alto dentro del periodo, 0,87 en el 2017 y 0,74 en el 2019; en cambio los valores de prueba ácida más bajos se registraron por parte de la empresa Laive SA, con 0,50 en el 2015, 0,44 en el 2016, 0,57 en el 2017 y 0,45 en el 2019; cabe señalar de que en el año 2018 el resultado se invirtió para las dos empresas, Laive SA supera a Leche Gloria SA con un índice de prueba ácida de 0,65 y Gloria desciende a índice de 0.60 .

Según el dictamen del año 2016 de Leche Gloria SA, siendo este el que mayor nivel de liquidez ácida mostró en la capacidad para cubrir sus obligaciones corrientes debido que, este indicador financiero excluye a los inventarios y en este caso equivale a un $47 \%$ del activo corriente, dejando un total (S/ 740'082,000) equivalente al 93\% para cubrir al pasivo corriente de un total de (S/ 792'497,000) esto significa que cuenta con los recursos como las cuentas por cobrar equivalente al $21 \%$, para cubrir la mayor parte de sus deudas a corto plazo.

\footnotetext{
"Visión de Futuro" Año 18, Volumen No 25 No 2, Julio - Diciembre 2021 - Pág 195 - 214

URL de la Revista: http://visiondefuturo.fce.unam.edu.ar/index.php/visiondefuturo/index

URL del Documento: https://visiondefuturo.fce.unam.edu.ar/index.php/visiondefuturo/issue/view/21

ISSN 1668 - 8708 - Versión en Línea

E-mail: revistacientifica@fce.unam.edu.ar
} 
En caso de Laive SA, el punto máximo que llegó en estos últimos 5 años fue en el 2018, y el dictamen de ese año detalla que los inventarios equivalen al $54 \%$ del total de activo corriente, excluyéndolo se obtiene un saldo de (S/84'180,000). Este resultado puede cubrir el $65 \%$ al total del pasivo corriente. Curiosamente este es el único periodo que Laive SA supera un 5\% a Leche Gloria SA en la liquidez ácida financiera, en consecuencia a que los inventarios abarca el 55\% del activo corriente siendo el responsable del bajón en la tendencia.

La prueba defensiva, detalla una amplia variación entre las empresas evaluadas del sector obteniendo resultados no favorables, según se muestra a continuación:

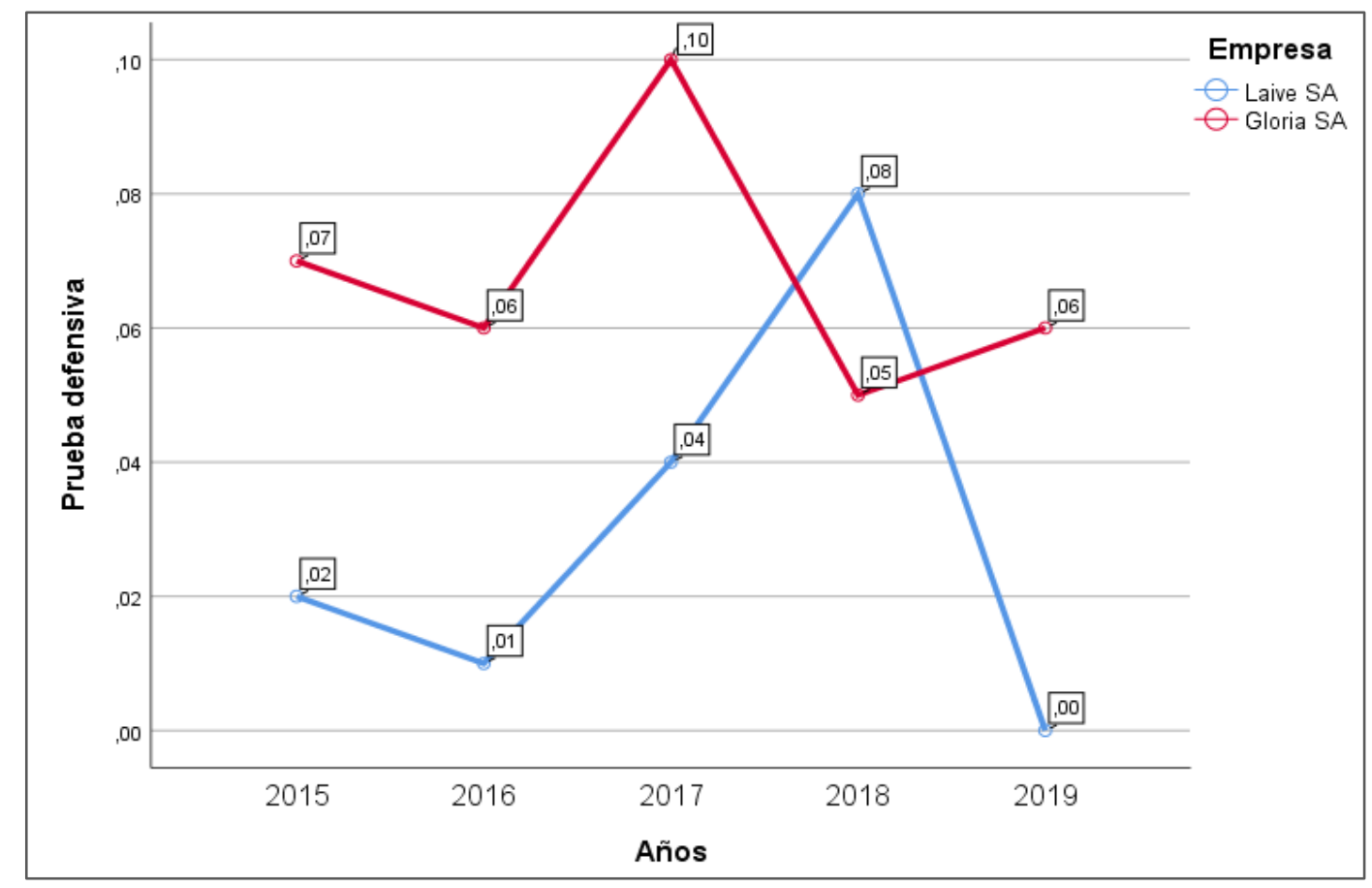

Figura $\mathrm{N}^{\circ}$. Análisis comparativo de la prueba defensiva

Fuente: Elaboración Propia a partir de datos de la BVL (2015 - 2019)

La figura 5, muestra los índices de prueba defensiva de las empresas del sector productivo lácteo en el periodo 2015 al 2019; los valores más altos fueron registrados por la empresa Leche Gloria SA, partiendo con un 0.07 en el año 2015, 0,06 en el año 2016, 0,10 en el 2017 el cual representa el índice de prueba defensiva más alto dentro del periodo y 0,06 en el 2019; en cambio los valores de prueba defensiva más bajos se registraron por parte de la empresa Laive SA, con 0,02 en el 2015, 0,01 en el 2016, 0,04 en el 2017 y 0,00 en el 2019; cabe señalar de que en el año 2018 el resultado se invirtió para las dos empresas, Laive SA supera a Leche Gloria SA con un índice de prueba defensiva de 0,08 y Leche Gloria desciende a índice de 0,06 . Por otro lado, el promedio fue mayor para Leche Gloria SA con 
un índice de 0,068, comparado al índice de prueba defensiva de 0,030 obtenido por Laive SA.

De acuerdo al dictamen del año 2017 presentado por Leche Gloria SA en la página web de la Bolsa de Valores de Lima, explica que el efectivo y equivalente de efectivo (compuestos por caja y bancos), fue el de mayor nivel en comparación a los demás resultados ya que solo puede cubrir el $10 \%$ de los pasivos a corto plazo, que principalmente eran las cobranzas de cheques pendientes en depósito (S/ 1'647,000) que ingresaron a caja y (S/ $\left.74^{\prime} 687,000\right)$ en cuentas corrientes tanto en soles y dólares sin devengar intereses. El nivel más bajo en los últimos periodos fue en el 2018, solo pudiendo cubrir las obligaciones financieras corrientes en un $5 \%$, siendo los depósitos establecidos con entidades financieras del mercado nacional, generando intereses de un promedio anual de $3 \%$, por un total de (S/ 46'977,000).

Por otro lado, reflejado en los dictámenes de Laive SA del año 2018 siendo el de mayor nivel de liquidez defensivo, logró una cobertura de caja y bancos en un $8 \%$ al pasivo corriente, siendo las cuentas corrientes del cual se disponía el $99 \%$ del efectivo, equivalente a (S/ 10’715,000). El año más bajo fue en el 2019 teniendo una cobertura del 0\%, donde en los documentos se explicó que esto es debido a que el dinero se utilizó para la compra de materia prima y suministros en mayor cantidad a años anteriores por el incremento de la demanda de productos.

\section{CONCLUSIÓN}

Se concluyó que el estudio logró analizar la situación financiera de las cuentas por cobrar y la liquidez mediante ratios de las únicas 2 empresas del sector lácteo que cotizan en la Bolsa de Valores de Lima. La empresa Leche Gloria SA contó con mayor capacidad para realizar las cobranzas con un promedio de 12 veces anuales en los últimos 5 años, debido al manejo de las políticas de cobranza y por la emisión de garantías por parte de clientes para reducir el riesgo crediticio. En caso de Laive SA, contó con una rotación de 9 veces al año de las cobranzas, siendo el de menor capacidad del sector lácteo, debido al deterioro de las facturas con 180 días de vencimiento equivalente al 20\% de las cuentas por cobrar.

Se dio por concluido al primer objetivo específico en cuanto a las cuentas por cobrar, que la empresa Leche Gloria SA, presentó una mejor suficiencia para la realización de las cobranzas, debido a un mejor control de las políticas de crédito porque contó con menor tiempo para la recaudación de lo exigible a sus clientes, con un promedio de 30 días en los últimos 5 años; mientras que Laive SA contó con un promedio de 38 días para realizar las cobranzas, lo cual la empresa procuró evaluar 2 veces al año los créditos otorgados según

\footnotetext{
"Visión de Futuro" Año 18, Volumen No 25 N², Julio - Diciembre 2021 - Pág 195 - 214

URL de la Revista: http://visiondefuturo.fce.unam.edu.ar/index.php/visiondefuturo/index

URL del Documento: https://visiondefuturo.fce.unam.edu.ar/index.php/visiondefuturo/issue/view/21

ISSN 1668 - 8708 - Versión en Línea

E-mail: revistacientifica@fce.unam.edu.ar
} 
el comportamiento crediticio, incluso utilizó las garantías depositadas por parte de los clientes.

Se determinó de acuerdo al segundo objetivo específico respecto al análisis de la liquidez mediante ratios financieros, que la empresa Leche Gloria SA, resultó con mejor capacidad de pago para hacer frente a sus obligaciones a corto plazo superando el rango estimado (mayor a 1), lo cual tiene un promedio de 1,62, mientras que Laive SA obtuvo un promedio menor de 1,28 a causa de las compras de materia prima, suministros y productos terminados para la venta.

También, la empresa Leche Gloria SA, presentó un promedio de 0.80 respecto a la prueba ácida, debido a que se excluyó el inventario equivalente al $47 \%$, por lo que siguió contando con recursos líquidos para cumplir sus obligaciones financieras; así mismo, la empresa Laive SA, tuvo un índice de 0.52 exceptuando el 54\% del inventario durante los periodos analizados, siendo este el de menor capacidad para pagar las deudas. Por último, se determinó que Laive SA, resultó con menor capacidad efectiva a corto plazo, lo cual obtuvo un promedio de 0.03 , porque el dinero se utilizó para las compras de materia prima y suministros en mayor cantidad, sin embargo, Leche Gloria SA, contó con una media de 0.07 , cubriendo solo el $10 \%$ del pasivo corriente, con la cobranza de cheques y depósitos en entidades financieras.

Se tuvo como limitaciones la obtención de información más específica y meticulosa respecto a la composición de los saldos de las cuentas por cobrar y las ventas, debido a la Pandemia del Covid - 19, y solo se utilizó la amplia información consolidada y presentada en la Bolsa de Valores de Lima del Perú.

Los aportes de este estudio son los siguientes:

Reevaluar los otorgamientos de créditos a los clientes de acuerdo a la antigüedad de la morosidad, coordinando con los clientes deudores para establecer plazos de pago acompañado de una carta de compromiso, con la finalidad de minimizar el riesgo crediticio de las empresas, la pérdida de dinero y ventas; además se puede optar por la implementación de descuentos a las facturas vencidas, esto podría ayudar a incrementar el efectivo líquido en menor tiempo para solventar el nivel de las obligaciones financieras.

Priorizar las ventas al contado o un periodo muy breve para aumentar la liquidez en menor tiempo, ofreciendo ventas como descuentos, buscando velar que los cobros sean menores a los periodos de pagos. También, se puede anticipar los cobros por factoring o disponer de una póliza de crédito, que ayudará a mantener la liquidez a pesar de los retrasos en los cobros.

\footnotetext{
"Visión de Futuro" Año 18, Volumen No 25 N², Julio - Diciembre 2021 - Pág 195 - 214

URL de la Revista: http://visiondefuturo.fce.unam.edu.ar/index.php/visiondefuturo/index

URL del Documento: https://visiondefuturo.fce.unam.edu.ar/index.php/visiondefuturo/issue/view/21

ISSN 1668 - 8708 - Versión en Línea

E-mail: revistacientifica@fce.unam.edu.ar
} 
Rediseñar los presupuestos realizados para identificar los gastos innecesarios, debido a que excederse en los gastos habituales suelen ser comunes y pueden afectar a la cuenta corriente; además de anticiparse a los periodos de pagos con el fin de no acumularse y que ponga a prueba la liquidez.

Las declaraciones a futuro dirigida hacia los investigadores es de utilizar en sus informes el tipo descriptiva - comparativa debido a que se analiza los resultados a profundidad sin alterar el resumen de todas las actividades realizadas por las empresas del sector en cada periodo contable.

\section{REFERENCIAS}

Amat Salas, O. (2017). Ratios sectoriales 2015. Editorial PROFIT. https://books.google.com.pe/books?id=fv4nDwAAQBAJ\&printsec=frontcover\&dq=RATI OS+SECTORIALES+2015+AMAT+2015\&hl=es\&sa=X\&ved=0ahUKEwiilN6ryN7eAhX O1FkKHcYuAFoQ6AEIJzAA\#v=onepage\&q=RATIOS\%20SECTORIALES\%202015\%2 OAMAT\%202015\&f=false

Bendezú Rivera, M. A. (2019). Estructura de capital y crecimiento empresarial: caso de la empresa Laive en el período 2004-2015. (Tesis para Obtener el Grado Académico de Magíster en Contabilidad con mención en Banca y Finanzas, Universidad Nacional Mayor de San Marcos). https://core.ac.uk/download/pdf/323350542.pdf

Bolsade Valores de Lima (2020). Empresas con Valores

Listado. http://documents.bvl.com.pe/mercempresasporsector.html\#

Castañeda Vásquez, Z. A. (2018). El apalancamiento financiero y su incidencia en la rentabilidad de la empresa Casa Polo S.A.C., año 2017. (Tesis para obtener el título profesional de Contador Público, Universidad César Vallejo). http://repositorio.ucv.edu.pe/handle/20.500.12692/27553

Córdova Pacheco, E. F., Veggro Cabrera, E. A., Trujillo Bravo, E. H. (2018). Valorización Leche Gloria S.A. Universidad del Pacífico. (Tesis para Obtener el Grado Académico de Magíster en Finanzas, Universidad del Pacífico, Escuela de Postgrado) https://repositorio.up.edu.pe/bitstream/handle/11354/2243/Edgard_Tesis_maestria_20 18.pdf?sequence $=1$ \&isAllowed $=y$

Díaz Narváez, V. P. y Calzadilla Núñez, A. (2015). Artículos Científicos, Tipos de Investigación y Productividad. Revistas Ciencia y Salud. http://www.scielo.org.co/pdf/recis/v14n1/v14n1a11.pdf

\footnotetext{
"Visión de Futuro" Año 18, Volumen No 25 No 2, Julio - Diciembre 2021 - Pág 195 - 214

URL de la Revista: http://visiondefuturo.fce.unam.edu.ar/index.php/visiondefuturo/index

URL del Documento: https://visiondefuturo.fce.unam.edu.ar/index.php/visiondefuturo/issue/view/21

ISSN 1668 - 8708 - Versión en Línea

E-mail: revistacientifica@fce.unam.edu.ar
} 
Durrah, O., Abdul Rahman, A. A., Ahsan Jamil, S. y Aldeen Ghafeer, N. (2016). Exploring the Relationship Between Liquidity Ratios and Indicators of Financial Performance: An Analytical Study on Food Industrial Companies Listed in Amman Bursa. International. Journal of Economics and Financial Issues, 6(2), 435-441. https://www.researchgate.net/profile/Syed_Ahsan_Jamil/publication/297158263_Explor ing_the_Relationship_between_Liquidity_Ratios_and_Indicators_of_Financial_Perform ance_An_Analytical_Study_on_Food_Industrial_Companies_Listed_in_Amman_Bursa/ links/56dd532408aef38babcbf20e/Exploring-the-Relationship-between-Liquidity-Ratiosand-Indicators-of-Financial-Performance-An-Analytical-Study-on-Food-Industrial-

Companies-Listed-in-Amman-Bursa.pdf

Gómez Rodríguez, D. T., Carranza Abella, Y. y Ramos Pineda, C. A. (2016). Revisión documental, una herramienta para el mejoramiento de las competencias de lectura y escritura en estudiantes universitarios. Revista Chakiñan. https://dialnet. unirioja.es/servlet/articulo?codigo=6294862

Guajardo Cantú, G. y Andrade de Guajardo, N. E. (2014). Contabilidad financiera. (6. ed.). Mc Graw Hill Education. https://www.academia.edu/25499343/LIBRO_ CONTABILIDAD_FINANCIERA_DE_GUAJARDO_CANTU

Herrera Freire, A. G., Betancourt Gongaza, V. A., Herrera Freire, A. H., Vega Rodríguez, S. R. y Vivanco Granda, E. C. (2016). Razones financieras de liquidez en la gestión empresarial para toma de decisiones. Quipukamayoc. https://revistasinvestigacion.unmsm.edu.pe/index.php/quipu/article/view/13249

Marsha, N. y Murtaqi, I. (2017). The Effect of Financial Ratios on Firm Value in the Food and Beverage Sector of The IDX. Journal of Business and Management. https://core.ac.uk/download/pdf/304294101.pdf

Moreno Fernández, J. A. (2014). Contabilidad de la estructura financiera de la empresa. (4. a ed.). Grupo Editorial Patria. https://books.google.com.pe/books?id=8NXhBA AAQBAJ\&lpg=PP1\&hl=es\&pg=PP1\#v=twopage\&q\&f=false

Munene, F. (2018). Accounts Receivable Management and Financial Performance of Embu Water and Sanitation Company Limited, Embu County, Kenya. Kenyatta University. https://irlibrary.ku.ac.ke/bitstream/handle/123456789/19512/Accounts\%20Receivable\% 20Management\%20and\%20Financial\%20Performance\%20of\%20Embu\%20Water\%20 and\%20Sanitation\%20Company\%20Limited,\%20Embu\%20County,\%20Kenya.pdf?seq uence $=1$

Nassaji, H. (2015). Qualitative and descriptive research: Data type versus data analysis. Language Teaching Research. https://scholar.google.com.pe/scholar?hl=es\&as_

\footnotetext{
"Visión de Futuro" Año 18, Volumen No 25 N², Julio - Diciembre 2021 - Pág 195 - 214

URL de la Revista: http://visiondefuturo.fce.unam.edu.ar/index.php/visiondefuturo/index

URL del Documento: https://visiondefuturo.fce.unam.edu.ar/index.php/visiondefuturo/issue/view/21

ISSN 1668 - 8708 - Versión en Línea

E-mail: revistacientifica@fce.unam.edu.ar
} 
sdt=0\%2C5\&as_vis=1\&q=descriptive+type\&btnG=\#d=gs_qabs\&u=\%23p\%3DuavLzbaz s8gJ

Opuku Ware, E. (2015). Liquidity Management and Its Effect on Profitability in a Tough Economy: (A Case of Companies Listed on the Ghana Stock Exchange). International Journal of Research in Business Studies and Management. https://cutt.ly/Rhn5Jum

Ortiz Taipe, I. L. (2019). Estrategias para reducir las cuentas por cobrar en la empresa de servicios, Lima 2018. (Tesis para optar por el título profesional de Contador Público). http://repositorio.uwiener.edu.pe/handle/123456789/3565

Pandoyo, M. (2019). The Influence of Account Receivable for Inventory of Income Before Tax. Ilomata International Journal of Tax \& Accounting. https://www.ilomata .org/index.php/ijtc/article/view/42/41

Peralta Gamboa, N. (2018). Políticas de créditos y cobranzas y la liquidez en la empresa Gráfica Biblos S.A. año 2016 - 2017. (Tesis para obtener el título profesional de Contador Público, Universidad Autónoma del Perú). http://repositorio.autonoma.edu.pe/bitstream/AUTONOMA/609/1/NORMA\%20PERALT A,\%20GAMBOA.pdf

Pineda Portugal, M. M. (2014). Importancia de la leche y productos Lácteos. Unsa Investiga. https://alicia.concytec.gob.pe/vufind/Record/UNSA_581906f12cc4aba76939720173533 f10/Description\#tabnav

Saíz Bear, M. (2017). Análisis Económico y Financiero del Sector Lácteo. Revista Universidad de Cantabria. https://repositorio.unican.es/xmlui/bitstream/handle/ 10902/12730/SAIZBEARMARIA.pdf?sequence=1\&isAllowed=y

Solano Duran, L. G. (2018). Cuentas por cobrar y su incidencia en la liquidez de la Empresa Mercantil S.A.C. año 2018. (Tesis para obtener el título profesional de Contador Público, Universidad Peruana de las Américas). http://repositorio.ulasamericas.edu.pe/bitstream/handle/upa/537/CUENTAS\%20POR\% 20COBRAR\%20Y\%20SU\%20INCIDENCIA\%20EN\%20LA\%20LIQUIDEZ\%20DE\%20L A\%20EMPRESA\%20MERCANTIL\%20S.A.C.\%20A\%C3\%910\%202018.pdf?sequence $=1$ \&isAllowed $=\mathrm{y}$

Soriano Rodriguez, A. M. (2014). Diseño y validación de instrumentos de medición. Repositorio Digital de la Ciencia y Cultura de El Salvador. https://core.ac.uk/download/pdf/47265078.pdf

Stam, N. y Westerman, W. (2018). Accounts Receivable Overdue and Market Dynamics: a Case Study. Central European Review of Economics and Management, 3, 7-41. https://mail.wsb.wroclaw.pl/index.php/WSBRJ/article/view/678

\footnotetext{
"Visión de Futuro" Año 18, Volumen No 25 N², Julio - Diciembre 2021 - Pág 195 - 214

URL de la Revista: http://visiondefuturo.fce.unam.edu.ar/index.php/visiondefuturo/index

URL del Documento: https://visiondefuturo.fce.unam.edu.ar/index.php/visiondefuturo/issue/view/21

ISSN 1668 - 8708 - Versión en Línea

E-mail: revistacientifica@fce.unam.edu.ar
} 
Wafula, W. M., Tibbs, C. Y., Ondiek, A. B. (2019). Average Collection Period and Financial Performance of Nzoia Water Services Company. International Journal of Multidisciplinary and Current Research. http://ijmcr.com/wpcontent/uploads/2019/05/Paper5273-279.pdf

Wiwik Afridah, M. (2018). Identifikasi Cash Ratio Rumah Sakit Islam Surabaya. Medical Technology and Public Health Journal. https://103.106.72.14/index.php /MTPHJ/article/view/760/598

\section{RESUMEN BIOGRÁFICO}

\section{Carlos Alberto Vásquez Villanueva}

Doctor en Administración (diploma en trámite), Universidad Nacional Federico Villareal, Lima. Maestría en Investigación y docencia Universitaria, Universidad Peruana Unión, Lima, Contador Público, Universidad Nacional de Tumbes. Categoría Docente Principal. Docente en La Universidad César Vallejo y la Universidad Peruana Unión en la Escuela de Contabilidad. Correo electrónico: carlosvasquezv19@gmail.com; https://orcid.org/0000-0002-0782-7364

\section{Otto Franklin Terry Ponte}

Doctor en Gestión Pública y Gobernabilidad (Universidad Cesar Vallejo), Master en docencia universitaria, Lima, Perú. Master en Gestión y Comunicación de Entidades Sociales y Solidarias, Universidad Abat Oliba CEU, Barcelona, España. Contador público - Abogado, Universidad Inca Garcilaso de la Vega, Lima, Perú. Correo electrónico: ottoterry@gmail.com, http://orcid.org/00000003-0717-8023

\section{Marylin Jhosmit Huaman Tito}

Egresada de la carrera de Contabilidad de la Universidad César Vallejo sede Ate, Lima, Perú. Residente en el distrito de Ate, laborando en la empresa inmobiliaria CBRE PERÚ ubicada en Santiago de Surco. Correo electrónico: mhuamanti@ucvvirtual.edu.pe, https://orcid.org/0000-0002$5882-151 X$

\section{Carlo Stefano Cerna Carrazco}

Egresado de la carrera de Contabilidad de la Universidad César Vallejo sede Ate, Lima, Perú. Residente en el distrito de Santa Anita, laborando en la empresa inmobiliaria CBRE PERÚ ubicada en Santiago de Surco. Correo electrónico: ccernaca99@ucvvirtual.edu.pe, https://orcid.org/0000-00032413-7098

\footnotetext{
"Visión de Futuro" Año 18, Volumen No 25 N² 2, Julio - Diciembre 2021 - Pág 195 - 214

URL de la Revista: http://visiondefuturo.fce.unam.edu.ar/index.php/visiondefuturo/index

URL del Documento: https://visiondefuturo.fce.unam.edu.ar/index.php/visiondefuturo/issue/view/21

ISSN 1668 - 8708 - Versión en Línea

E-mail: revistacientifica@fce.unam.edu.ar
} 